\title{
COMPARATIVE EVALUATION OF CLEANING EFFICACY OF THE ROOT CANAL BY K-FILE AND PROTAPER NEXT, HYFLEX EDM ROTARY SYSTEM AN IN VITRO STUDY
}

\author{
${ }^{1}$ Assistant Professor, Department of Conservative Dentistry, Dental College, RIMS, Imphal. \\ ${ }^{2}$ Assistant Professor, Department of Conservative Dentistry, Dental College, RIMS, Imphal. \\ ${ }_{3}^{3}$ Assistant Professor, Department of Conservative Dentistry, Dental College, RIMS, Imphal. \\ ${ }_{4}^{4}$ Associate Professor, Department of Oral Pathology, Dental College, RIMS, Imphal. \\ 5 Professor and HOD, Department of Conservative Dentistry, Dental College, RIMS, Imphal.
}

Takhellambam Premlata Devi ${ }^{1}$, Sh. Priyadarshini², Umesh Kumar Dharmani ${ }^{3}$, Ngairangbam Sanjeeta ${ }^{4}$, Deepak B. S5

\begin{tabular}{l}
\hline ABSTRACT \\
BACKGROUND \\
The aim of this study was to compare the cleaning efficacy of manual instrumentation, Protaper Next and Hyflex EDM Rotary file \\
systems.
\end{tabular}

\section{MATERIALS AND METHODS}

Sixty mandibular premolar teeth were selected and their pulp tissue was removed after coronal access. The root canals were filled with a dye (India ink) and allowed to dry for 48 hours. The specimens were randomly divided into three experimental groups, Group One: Stainless steel K file ( $n=20)$, Group Two: ProTaper Next ( $=20)$, Group Three: Hyflex EDM $(n=20)$. Instrumentation was done with Stainless steel K file Hand, ProTaper Next and Hyflex EDM rotary instruments. The teeth were longitudinally sectioned and evaluated according to the amount of remaining dye.

\section{RESULTS}

The data were statistically analysed using Kruskal-Wallis One-Way Analysis of Variance and a P value of $<0.05$ was taken as statistically significant. Instrumentation with stainless steel K-files showed maximum amount of dye in the middle and apical third followed by ProTaper Next and Hyflex EDM; however, in the coronal third there were no significant differences between the three experimental groups.

\section{CONCLUSION}

Hyflex EDM showed better cleaning efficacy when compared to other instrumentation techniques, especially in middle and apical one-third.

\section{KEYWORDS}

Cleaning Efficacy, Dye, Hyflex EDM, ProTaper Next.

HOW TO CITE THIS ARTICLE: Devi TP, Priyadarshini S, Dharmani UK, et al. Comparative evaluation of cleaning efficacy of the root canal by K-file and Protaper Next, Hyflex EDM rotary system an in vitro study. J. Evolution Med. Dent. Sci. 2016;5(100):7365-7369, DOI: $10.14260 /$ jemds/2016/1667

\section{BACKGROUND}

Success in endodontic treatment depends on adequate biomechanical preparation of the root canal space. Its aim consists of cleaning of root canal and its ramifications, removing most of debris to create an ideal condition which lead to healing and tissue regeneration. The main objective of root canal preparation is to remove vital pulp tissue, residual necrotic materials, debris and infected dentin and thus eliminate most of the micro-organisms from the root canal system. ${ }^{1}$

Over the years, a variety of instruments and techniques have been proposed to reach the goal of proper cleaning and shaping. In recent years, a greater awareness of the complexities of the root canal system has led to the development of newer techniques, instruments and materials. $^{2}$

Financial or Other, Competing Interest: None.

Submission 08-11-2016, Peer Review 01-12-2016,

Acceptance 09-12-2016, Published 15-12-2016.

Corresponding Author:

Dr. Takhellambam Premlata Devi,

Assistant Professor,

Department of Conservative Dentistry and

Endodontics, Dental College,

RIMS, Imphal-795004.

E-mail: tpremlatadevi@yahoo.com

DOI: $10.14260 /$ jemds $/ 2016 / 1667$
With the development of various Nickel-Titanium (NiTi) rotary file systems have further ensured more predictable outcomes of the treatment. The cleaning capabilities of different NiTi rotary systems varies because of the different cross-sections and blade designs of each system.3,4 One of the most popular single-file systems is ProTaper Next (Dentsply Maillefer, Ballaigues, Switzerland), which incorporates the convergence of 3 significant design features, that is progressive percentage tapers on a single file, M-wire technology and offset design which is used in continuous motion.

Another newly developed file system is Hyflex EDM (NiTi) files is produced with its unique properties to a breakthrough technology called "Electrical Discharge machining" by an innovative methodology, which uses spark erosion to harden the surface of the NiTi file resulting in superior fracture resistance, improved cutting efficiency and also offer trusted controlled memory effect and regenerative properties. The aim of this study was to compare the efficacy of instrumentation using ProTaper Next and Hyflex EDM to be compared with Stainless Steel K-files in cleaning of root canals. The proposed Null Hypothesis for the study is that there will be difference between the groups. 


\section{MATERIALS AND METHODS}

Sixty freshly extracted human mandibular premolar teeth that were sacrificed for orthodontic and periodontal purpose were used. The inclusion criteria were the single rooted mandibular premolar teeth with single root canal and apical foramen with root curvature between $0^{\circ}$ and $10^{\circ}$. Teeth with signs of crack, internal and external resorption, root caries, canal calcifications and open apices were excluded from the study. The teeth were randomly divided into 3 experimental groups with 20 teeth in each group.

The debris and soft tissue remnants were cleaned from external root surface and then stored in a $0.9 \%$ physiological saline solution until use.

Coronal access cavity preparation was done with diamond burs. Patency was assured with a size $10 \mathrm{~K}$-file after removal of the pulp tissue with Hedstrom files (Maillefer Instruments Ballaigues - Switzerland) associated with $0.5 \%$ sodium hypochlorite irrigation. Additional irrigation was performed with $5 \mathrm{~mL}$ of distilled water and the canals dried. After drying they were filled with India ink (Lobal Chemie Laboratory reagants and Fine Chemical, India) by using a plastic disposable endodontic irrigating syringe gauge 27 needle. At the same time, a suction tip was placed at the root apex to draw the ink through the root canal system. The appearance of ink at the apical foramen indicated the end of the process.

The dye was allowed to dry for 48 hours and then the working length was obtained by initial measurement with 15 K-file (Mani, Tochigi, Japan) introduced until the apical foramen and subtracting $1 \mathrm{~mm}$.

The samples were then randomly divided into the following groups depending upon the file system used:

Group 1 - $(\mathrm{n}=20)$ Teeth were prepared with stainless steel Kfile (Mani INC, Tochigi, Japan). Coronal flaring was performed with Gates Glidden burs \#2 and \#3.
Instrumentation was done with double flare technique using balanced force motion, till apical size 30 .

Group 2 - $(\mathrm{n}=20)$ Teeth were prepared with ProTaper Next (Dentsply Maillefer, Ballaigues, Switzerland) files in sequential order till $\mathrm{x} 3$ at the working length according to the manufacturer's instructions using an endodontic engine (XSMART Plus (Dentsply, Maillefer) at $250 \mathrm{rpm}$.

Group 3 - (n = 20) Hyflex EDM One File 25/(ColteneWhaledent, Allstetten, Switzerland) was used according to the manufacturer's recommendations using CanalPro CL Motor (Coltene) at $500 \mathrm{rpm}$.

All the canals were prepared by the same operator. Irrigation was performed with $3 \%$ sodium hypochlorite solution. After instrumentation, the teeth were longitudinally sectioned with a carborundum disk (Dentorium-InternationalNY-USA). The hemisections obtained were fixed in a paper leaf with adhesive tape with root canal wall turned upwards. The canals were divided into three thirds (Cervical, middle and apical) for individual evaluation.

The canal cleaning efficacy was evaluated employing a magnifying glass with $4 \mathrm{x}$ magnification and data were registered on the basis of dye removal by numerical scores.

0 - No remaining dye.

1- Almost complete dye removal.

2- Partial dye removal.

3- No dye removal.

The data were statistically analysed using Statistical Package for Social Science (SPSS, version 16). Analysis was performed using Kruskal-Wallis One-Way Analysis of Variance and a $P$ value of $<0.05$ was taken as statistically significant.

\section{RESULTS}

\begin{tabular}{|c|c|c|c|c|c|c|c|c|c|}
\hline \multirow{3}{*}{ Instrument } & \multicolumn{9}{|c|}{ Region } \\
\hline & \multicolumn{3}{|c|}{ Coronal } & \multicolumn{3}{|c|}{ Middle } & \multicolumn{3}{|c|}{ Apical } \\
\hline & $\begin{array}{c}\text { Mean } \\
\text { (SD) }\end{array}$ & Min. & Max. & $\begin{array}{c}\text { Mean } \\
\text { (SD) }\end{array}$ & Min. & Max. & $\begin{array}{c}\text { Mean } \\
\text { (SD) }\end{array}$ & Min. & Max. \\
\hline $\begin{array}{c}\text { Stainless } \\
\text { Steel K-file }\end{array}$ & .11547 & 0 & 2 & .15620 & 0 & 2 & .17397 & 0 & 3 \\
\hline ProTaper Next & .09798 & 0 & 1 & .11662 & 0 & 2 & 10198 & 0 & 1 \\
\hline Hyflex EDM & .08718 & 0 & 1 & .09522 & 0 & 1 & .11662 & 0 & 1 \\
\hline
\end{tabular}

Table 1. Mean (Standard Deviation) Dye Removal Score After the Use of the Different Instruments by Regions

\begin{tabular}{|c|c|c|c|c|c|}
\hline & \multirow{3}{*}{ Instrument } & \multirow{3}{*}{$\mathbf{N}$} & \multicolumn{3}{|c|}{ Region } \\
\hline & & & Coronal & Middle & Apical \\
\hline & & & Mean Rank & Mean Rank & Mean Rank \\
\hline \multirow{3}{*}{$\begin{array}{c}\text { Dye Removal } \\
\text { Score }\end{array}$} & $\begin{array}{c}\text { Stainless } \\
\text { Steel K-file }\end{array}$ & 20 & 39.80 & 46.84 & 53.46 \\
\hline & $\begin{array}{c}\text { ProTaper } \\
\text { Next }\end{array}$ & 20 & 39.32 & 35.28 & 31.12 \\
\hline & $\begin{array}{l}\text { Hyflex } \\
\text { EDM }\end{array}$ & 20 & 34.88 & 31.88 & 29.42 \\
\hline \multicolumn{3}{|c|}{ 'P' Value } & $\begin{array}{c}\mathrm{p}>0.05 \\
\text { Not Significant }\end{array}$ & $\begin{array}{c}\mathrm{p}<0.05 \\
\text { Significant }\end{array}$ & $\begin{array}{c}\mathrm{p}<0.01 \text { Highly } \\
\text { Significant }\end{array}$ \\
\hline
\end{tabular}


The Kruskal-Wallis test showed that there was a statistically significant difference between the different instruments in dye removal efficacy with a mean rank of 53.46 for Stainless Steel K-file, 31.12 for ProTaper Next and 29.42 for Hyflex EDM for apical region and middle region $(\mathrm{P}<0.05$ with a mean rank 46.84 for Stainless Steel K-file, 35.28 for ProTaper Next and 31.88 for Hyflex EDM).

The analysis of the results demonstrated that the overall cleaning efficacy is best with Hyflex EDM followed by ProTaper Next and Stainless Steel K-file has lowest cleaning efficacy.

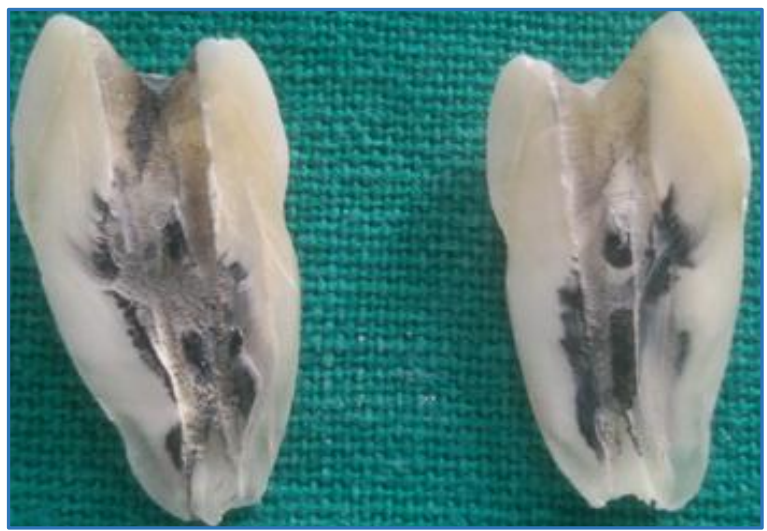

Figure 1. Manual K-File Preparation

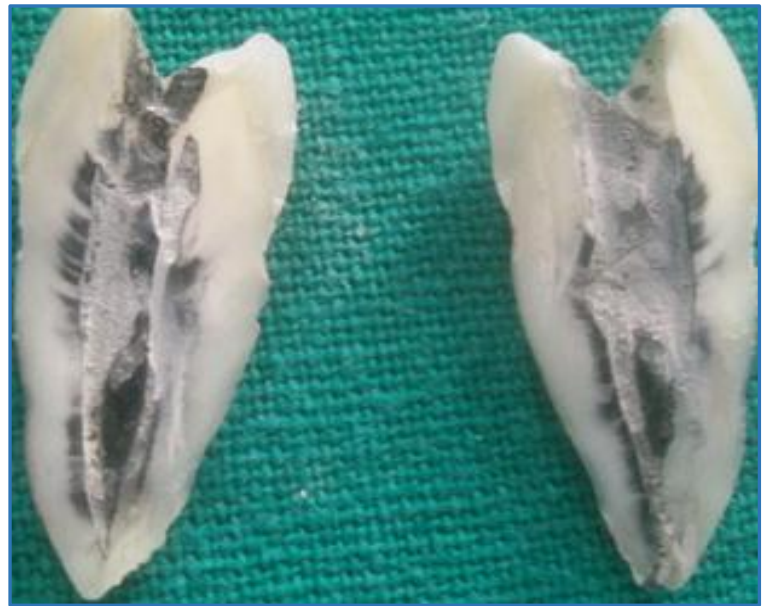

Figure 2. ProTaper Next Preparation

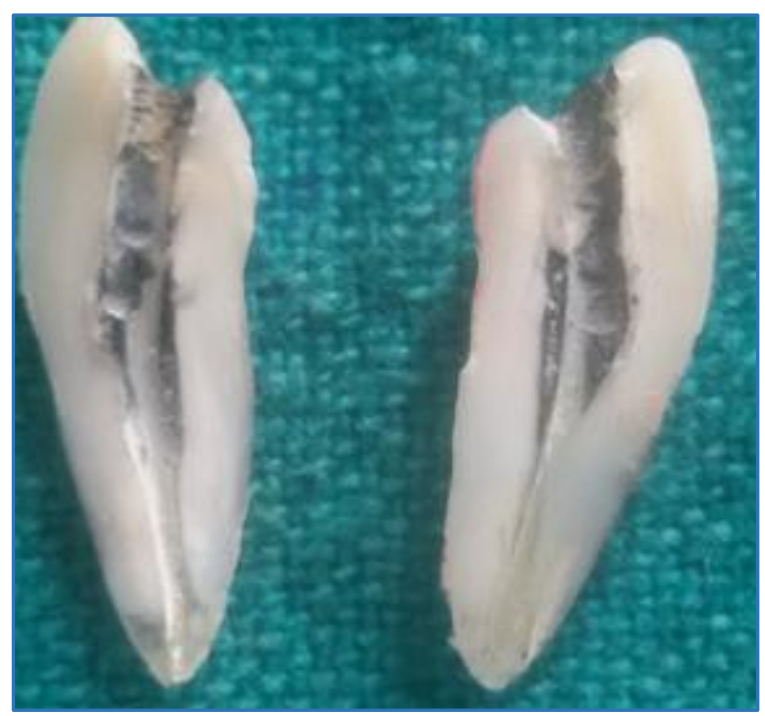

Figure 3. Hyflex EDM Preparation

\section{DISCUSSION}

Over the years many instruments with varying designs made of different materials with systems oriented techniques have been created for effective attainment of mechanical and biological objective of root canal treatment. However, as in the case of ProTaper Next and Hyflex EDM systems, few studies have evaluated its performance in endodontic filing. Thus, the effectiveness of instrumentation of the root canal walls was evaluated in this study comparing the Hyflex EDM, ProTaper Next system with Stainless Steel K-file. Though the instruments in conjugation with irrigation plays the major role in debridement, still it will not sufficiently clean the complex root canal system. In the present study, none of the instrumentation techniques achieved total cleansing of root canal. This finding is supported by study carried out (Heards and Walton, ${ }^{5}$ Langland $\mathrm{K}$ et $\mathrm{al}^{6}$ ).

Analysis of the cleaning ability of some instrumentation systems by removal of the dye adhered to the root canal walls has been conducted in the literature by some authors such as Gonclaves et al. ${ }^{7}$ This technique does not allow differentiation between the areas of debris (Dentin fragments and pulp remnants) and the smear layer, which is possible by utilisation of Scanning Electron Microscopy (SEM).3,4,8

Considering the mechanical action of the instruments tested, the primary aim of this study and the cleaning ability of irrigating solutions, isolated utilisation of $\mathrm{NaOCl}$ without addition of chelants was chosen, since the cleaning effect should be restricted to removal of instrumentation debris by the hydrodynamics of irrigation and dissolution of the organic remnants by the chemical action of this irrigating solution.

The cleaning efficacy of canal instrumentation has been evaluated either by a bacteriologic method or by observing remaining tissue debris. In the present study, cleansing of the root canals were evaluated for dye removal from the interior of the root canals as numerical scores ranging from $0-3$. This criterion also was used in other studies. ${ }^{7}$

In the present study neither of the instrumentation techniques achieved total dye removal from the interior of the root canals and consequent complete cleaning. This finding is supported by study carried out (Schafer E 2003, ${ }^{3}$ Ahlquist M 2001,8 Barbizam JV 20029).

In addition, it was observed that some areas were uninstrumented, indicating that complete canal instrumentation was not achieved. Moreover, an irregular secondary dentine is associated with the physiological aging of the root, ${ }^{10}$ so that surface morphology especially in the apical region is far from smooth. 11 This could contribute to higher dye scores in the apical third of the canal.

Comparative studies between manual and rotary instruments in terms of cleaning efficacy have found that hand instrumentation leave more debris in all levels, which is highest in the apical third. ${ }^{8}$

Some studies have reported the advantages of manual instrumentation over rotary files regarding root canal wall preparation.3,9 However, other studies have reported better results with rotary NiTi systems. ${ }^{12}$

In the present study K-file showed least ink removal in coronal, middle and apical third of the root canal, which could be attributed to the 0.02 taper and poor cutting efficacies. ${ }^{13}$

The new Hyflex ${ }^{\mathrm{TM}}$ EDM Files, which is also a successor of Hyflex $^{\mathrm{TM}}$ CM nickel-titanium (NiTi) files (Coltene-Whaledent, 
Allstetten, Switzerland) have completely new properties and fewer files due to their innovative manufacturing process using electric discharge machining. As a result of EDM process, the file is extremely flexible and with variable cross-section design (Quadratic at tip, trapezoidal in middle and triangular cross-section at top) contributes to high breakage resistance and also controls the materials memory (a complex heating and cooling treatment), which can significantly reduce the risk of ledging, transportation and perforation.

The unique combination of flexibility and fracture resistance makes it possible to reduce the number of files required for cleaning and shaping during root canal treatments without having to compromise preservation of the root canal anatomy. ${ }^{14}$

With no literature available for the use of Hyflex EDM file, we followed the manufacturer's instructions for preparation of the root canal.

The Protaper Next file system, which is a successor to the ProTaper Universal system includes a set of five files with varying lengths, design and taper. X1 and X2 files have both increasing and decreasing percentage taper on a single file.

Additionally, the files have a centered mass of rotation from D1 - D3 and an offset mass of rotation between D4 - D16. The X3, X4 and X5 files have a fixed taper from D1 - D3; thereafter, the taper decreases on their active portions. These design features aid in minimising the contact between the file and dentin, which gradually decreases the chances of unwanted taper lock and the screw effect leading to increased efficiency. The cleaning efficacy of ProTaper Next can also be attributed to its offset design, which has three major advantages. The swaggering effect helps in lesser file engagement. It also offers more cross-sectional space for improved cutting, loading and augering debris out of a canal. It also results in the reduction of the probability of lateral compaction of debris and the blockage of the root canal system, thus ensuring the maintenance of the patency inside the root canals.

In the present study, ProTaper Next shows slightly cleaner in apical than the middle area which is not statistically significant. Studies also claimed that when instrumentation is performed with files of greater taper, a pseudo sense of snug fit is created because of the binding of the flutes in the coronal portion, whereas the apical portion may lie uninstrumented.15

The advantages of rotary NiTi instruments include the facilitation of the canal preparation, ${ }^{16}$ adequate enlargement for better penetration of root canal irrigants, preservation of the shape of curved canals ${ }^{17}$ and production of smooth surfaces in minimal time. ${ }^{16}$ American Dental Association defined the taper of endodontic files as 0.02 in 1981 and allowed the variation within $0.05 \mathrm{~mm}$ in $2001 .{ }^{18}$ So there are 3 types of tapers: constant taper, progressive taper (from apical to coronal) and decreasing taper.4,19 It is claimed that progressive taper increases the flexibility of files, while decreasing taper makes files much stiffer. ${ }^{20}$

In the present study, the cleaning efficacy of Hyflex EDM (Mean dye removal score 34.88 at coronal, 31.88 at middle and 29.42 at apical region) was found to be superior to ProTaper Next (Mean Dye removal score 39.32 at coronal, 35.28 middle and apical 31.12), p value $<0.05$ and $<0.01$ at middle and apical region respectively. Hyflex EDM and manual systems showed higher cleaning efficacy in coronal and middle thirds and exhibited maximum dye in apical thirds of the root canals, which is a finding in compliance with the study carried out by Katge $\mathrm{F}$ et al. ${ }^{13}$

Root canals are irregular complicated systems that are difficult to clean and shape. These problems have resulted in a wide search for innovative materials, instruments and techniques to obtain a clean, disinfected, debris free canal for obturation.

\section{CONCLUSION}

Hyflex EDM and ProTaper Next systems showed better cleaning ability in the middle and apical third as compared to manual instrumentation (K-file) and the results were statistically significant. There was no statistically significant difference in between Hyflex EDM, ProTaper Next and Stainless Steel K-file instrumentations in coronal third.

\section{REFERENCES}

1. Siqueira JF, Araujo MC, Garcia PF, et al. Histological evaluation of the effectiveness of five instrumentation techniques for cleaning the apical third of root canals. Journal of Endodontics 1997;23(8):499-502.

2. Boruah LC, Bhuyan AC, Kataki R. Histological evaluation of the effectiveness of four instrumentation techniques for cleaning the apical third of root canals-an invitro study. J Conserv Dent 2006;9(4):134-9.

3. Schäfer E, Schlingemann R. Efficiency of rotary nickeltitanium K3 instruments compared with stainless steel hand K-Flexofile. Part 2. Cleaning effectiveness and shaping ability in severely curved root canals of extracted teeth. Int Endod J 2003;36(3):208-17.

4. Schäfer E, Vlassis M. Comparative investigation of two rotary nickel-titanium instruments: ProTaper versus RaCe. Part 1. Shaping ability in simulated curved canals. Int Endod J 2004;37(4):229-38.

5. Heard F, Walton RE. Scanning electron microscope study comparing four root canal preparation techniques in small curved canals. Int Endodontic Journal 1997;30(5):323-31.

6. Langeland K, Liao K, Pascon EA. Work-saving devices in endodontics: efficacy of sonic and ultrasonic tecniques. J Endod 1985;11(11):499-510.

7. Gonçalves SB, Brosco VH, Bramante CM. Comparative analysis of rotary (GT) and manual root canal preparation and association of both techniques in instrumentation of flattened root canals. J Appl Oral Sci 2003;11(1):35-9.

8. Ahlquist $\mathrm{M}$, Henningsson $\mathrm{O}$, Hultenby $\mathrm{K}$, et al. The effectiveness of manual and rotary techniques in the cleaning of root canals: an SEM study. Int Endod J 2001;34(7):533-7.

9. Barbizam JV, Fariniuk LF, Marchesan MA, et al. Effectiveness of manual and rotary instrumentation techniques for cleaning flattened root canals. J Endod 2002;28(5):365-6.

10. Wakabayashi H, Matsumoto K, Nakamura $\mathrm{Y}$, et al. Morphology of the root canal wall and arrangement of underlying dentinal tubules. Int Endod J 1993;26(3):1538.

11. Bechelli C, Orlandini ZS, Colafranceschi M. Scanning electron microscopic study on the efficacy of root canal wall debridement of hand versus lightspeed instrumentation. Int Endod J 1999;32(6):484-93. 
12. Guelzow A, Stamm O, Martus P, et al. Comparative study of six rotary nickel-titanium systems and hand instrumentation for root canal preparation. Int Endod J 2005;38(10):743-52.

13. Katge F, Patil D, Poojari $M$, et al. Comparison of instrumentation time and cleaning efficacy of manual instrumentation, rotary systems and reciprocating systems in primary teeth: an in vitro study. J Ind Soc Pedod Prev Dent 2014;32(4):311-6.

14. Pirani C, Iacono F, Generali L, et al. Superficial features, metallurgical analysis and fatigue resistance of innovative electro discharge machined NiTi rotary instruments. Int Endod J 2016;49(5):483-93.

15. Lumley PJ. Cleaning efficacy of two apical preparation regimens following shaping with hand files of greater taper. Int Endod J 2000;33(3):262-5.
16. Hulsmann M, Peters OA, Dummer PMH. Mechanical preparation of root canals: shaping goals, techniques and means. Endod Top 2005;10(1):30-76.

17. Schäfer E, Schulz-Bongert U, Tulus G. Comparison of hand stainless steel and nickel titanium rotary instrumentation: a clinical study. J Endod 2004;30(6):432-5.

18. Chesler MB, Tordik PA, Imamura GM, et al. Intra manufacturer diameter and taper variability of rotary instruments and their corresponding gutta-percha cones. J Endod 2013;39(4):538-41.

19. Gergi R, Abou RJ, Osta $N$, et al. Taper preparation variability compared to current taper standards using computed tomography. Int J Dent Article ID 265695, 2012;2012:4.

20. Bergmans L, Van Cleynenbreugel J, Beullens M, et al. Progressive versus constant tapered shaft design using NiTi rotary instruments. Int Endod J 2003;36(4):288-95. 